believes that spiders make use of this faculty in the construction of their webs; it is a question which I shall not examine. He also thinks that the instinct which causes aquatic birds to smooth down their feathers is owing to this faculty; so that we should also attribute to it cleanliness. For example, the care that the cat takes to conceal its ordure; the attention that horses pay always to depose their excrement in the same place, as if they knew that by acting otherwise they would render the pasture unfit for their nourishment; for it is a fact, that horses never eat the grass which has grown around their excrement, although they will eat that which grows around the excrement of cows. I have been brought up in the country, and have observed all this without intention. As we cannot bring forward intelligence in order to explain this attention on the part of horses, we must attribute it to an instinct of which our organ is the instrument.

There is another impulsion, which causes the cow to eat the after-birth of its calf; another, which causes the bird to throw out of its nest the ordure of its little ones, and to go themselves to a certain distance to deposit their own. This precaution only exists in birds with regard to their nests. Must we attribute to the same organ the repugnance of man for these things? 1 do not know. The sentiment of disgust, upon which phrenology has not sufliciently disserted, is a very remarkable thing. There are men and women to whom nothing is repugnant; who touch and look at all kinds of ordure, wounds, ulcers, \&c.; others whose stomachs turn at the sight of every thing disgusting; others who romit if they imagine that they have swallowed a hair, an insect, anything which inspires them with disgust. A common saying is, "They have the stomach of sensibility;" but the stomach is only excited by the brain in this case. The question then is this,-Whether the sentiment of disgust, as well as that of cleanliness, depends on the organ of order or of any other? Certain persons hare a horror of mice and rats, others of spiders, others of reptiles, \&c. We have seen in Paris a Prussian officer who could not see old women, a cat, or a sewing thimble, without falling into convulsions. In physiology they call it idiosyncracy, but this word does not explain anything. We have to determine whether these dislikes depend on an organ, and what is the organ. It is only by observation that we can solve this question. For my part I am not sufficiently rich in facts to pronounce upon these questions. You know that I promised to communicate to you my doubis as well as my convictions.

\section{PARTURITION OF A MALE CHILD AND A BLIGHTED FOETUS.}

\section{To the Editor of 'THE LANCET.}

SIR :-Cases similar to the following, I believe, seldom occur, though some are recorded. On the 28th of May last, I was called to attend Mrs. G., who was just taken in labour. Her age was about 30 years, and she was the mother of two children. Shortly after my arrival, a large, healthy child was born, and the uterine efforts continued very severe, but the placenta was not expelled. After waiting a short time, I passed my finger along the cord to the uterus, when I discovered a soft mass, not unlike distended membranes, protruding from it. During a strong pain, I made slight extension on the cord, when the placenta, together with the mass, immediately came away. On examining the latter, I found it to consist of a small male foetus, about five inches in length, surrounded by about three ounces of fluid. The integument of the foetus was softened, and presented just such an appearance as might be expected from long maceration; it did not give off any unusual odour. On turning to Burns' "Midwifery," page 168, I find the following observations on the subject:-

"In the human subject, only one ovum is generally impregnated by one seminal application, but sometimes two or more may be carried down into the uterus, and even after one orum has reached the uterus, and grown to a certain degrec within it, we find that it is possible for a second to be excited into action, and brought down into the womb, where it is nourished and supported; but it is not yet ascertained what the greatest interral between the two conceptions may be. It appears to be ascertained that a woman may not only bear two liring children of different ages, or of different colours, but also, that when a child dies in utero, it may be retained, and a new conception occur."

In a note, the following case is quoted:-

"Percy mentions the case of a woman whose child in utero seems to have become blighted, after motion had been perceived. At the end of seven weeks, from this time, she felt anew the incipient symptoms of pregnancy, and went on to the full time from the second date, when she bore a child, small, but lively. After the placenta had come away, a mass was expelled, in the midst of which was found a female foetus, corresponding in size with one of the fourth month, the period at which motion had ceased to be felt in the first instance."(Rev. Med., p. 129.) On enquiry, I could merely learn that my patient expected to be confined at least three months before the event occurred. I am, Sir, yours, respectfully, L. Owen Fox.

Broughton, Stockbridge, Hants, Sep. 7 th. 